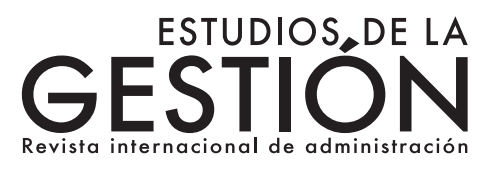

\title{
Ganamos o perdimos: análisis del Î́ndice de Desarrollo Humano, 1990-2015
}

\author{
O. Pablo de la Torre Neira \\ Pontificia Universidad Católica del Ecuador (Quito-Ecuador) \\ pdelatorre@mipro.gob.ec
}

Fecha de presentación: 7 de noviembre de 2017 • Fecha de aceptación: 6 de enero de 2018 Artículo de opinión 
L

as comunidades rurales, periféricas o urbanas se han incorporado en este milenio como actores vivos de las soluciones a la crisis. Unas con más creatividad, otras más efectivas en resultados y algunas fuertes en impacto. En su mayoría, han echado mano a su pasión para encontrar soluciones alternativas incidiendo directamente en los procesos productivos que las organizaciones con y sin fines de lucro han implementado o quisieran implementar. Sin embargo, todas disponen de la tecnología, cualquiera que sea el avance en su entorno, para diseñar y emprender esas ansiadas soluciones. Como resultado primario se logra que la pasión unida a la tecnología sea el común denominador de la innovación y creatividad; por ello las ideas y los valores de quienes emprenden estas soluciones son fundamentales para cambiar el modo de hacer las cosas y los resultados e impacto que necesitan esas comunidades. A las comunidades que emprenden de esta forma se les conoce como nuevas, modernas y proactivas en la búsqueda de caminos más efectivos y más eficientes para satisfacer las necesidades. Desde el siglo pasado, la modernización ha tenido importancia, pero ahora cobran mayor relevancia la invención y el desarrollo de modos distintos de hacer las cosas gracias a velocidad tan vertiginosa con la que se ejecutan.

Debemos ser objetivos y para ello utilizaremos herramientas modernas y de conocimiento global para demostrar esta idea. Para volver objetiva esta diferencia relativa, entre modernos y atrasados, vamos a utilizar varios índices. Empezaremos con el Índice de Desarrollo Humano (IDH). Si el desarrollo humano es definido por la Organización de Naciones Unidas como "el proceso de ampliación de las opciones de la gente” (PNUD 1998, Prólogo), las sociedades más modernas serán:

- Socialmente responsables, por aumentar la capacidad de satisfacer las necesidades de las personas, es decir, de auspiciar la capacidad para crear y acumular conocimiento. 
- Favorecedoras de un desarrollo sostenible de las potencialidades productivas tanto para las generaciones actuales como para las futuras.

- Estimulantes de la aplicación de capacidades individuales y colectivas para acometer nuevas iniciativas.

- Creadoras de condiciones de accesibilidad de todos los niveles de las poblaciones a servicios básicos $\mathrm{y}$,

- Distribuidoras equitativas del acceso de la población a bienes y servicios. El PNUD y su Informe 2016 señalan que Noruega, Australia, Suiza, Alemania, Dinamarca, Singapur, Países Bajos, Irlanda, Islandia, Canadá y Estados Unidos ocupan los diez primeros lugares en el desarrollo humano. Son, sin duda alguna, los países considerados modernos dada la amplitud de la aplicación práctica de innovaciones técnicas y organizativas de todo tipo. Coincide que son, a la vez, sociedades con prominencia del sector privado en las actividades productivas y con alta capacidad normativa y reguladora del sector público. Son los países de más alto desarrollo humano los que aseguran mejor a su gente con relación a servicios públicos, salud, educación, seguridad, capacidad de compra y especialmente acceso a la actividad productiva (PNUD 1998, 107).

Al observar los resultados del informe del PNUD resulta evidente que todos los países usan el mecanismo del mercado para la asignación de recursos, preservando para el sector público la fijación de normas y la aplicación de mecanismos reguladores y correctivos en casos de fallas del mercado. La política económica de los gobiernos se orienta a corregir factores de distorsión que afectan la eficiencia de la asignación y, por ende, el bienestar de la gente, tal y como el pensamiento económico moderno lo puntualiza.

Los países de más alto desarrollo humano, especialmente los que ocupan entre los diez primeros puestos en el IDH, han transformado la estructura de sus Estados para adaptarlos a circunstancias cambiantes. En la década de 1980, comenzando en el Reino Unido, se generalizó una restitución de actividades productivas desde los sectores públicos hacia los privados. Se afinaron estructuras de la administración pública para jugar mejor su rol normativo y regulador para corregir deficiencias de asignación de recursos en situaciones de limitación de la competencia como el de los monopolios naturales y las fallas de mercado. La extensión e intensidad de la regulación per- 
manece como objeto de debate inclinándose hacia el llamado neoliberalismo por niveles mínimos (Crozier 1989, 108-110).

Los países que mayor éxito han tenido en introducir estas estructuras han experimentado incrementos significativos y rápidos de desarrollo humano en las últimas tres décadas. Tal es el caso del Liechtenstein $\left(6^{\text {to }}\right)$, Corea del Sur $\left(12^{\mathrm{do}}\right)$, Grecia $\left(21^{\mathrm{ro}}\right)$, Eslovaquia $\left(31^{\mathrm{ro}}\right)$ y Azerbaijan $\left(67^{\mathrm{mo}}\right)$.

Por el contrario, los países con predominio público en la producción de bienes y servicios, como aquellos que hasta años recientes mantuvieron sistemas de economía centralmente planificada, con participación privada marginal, encubierta o reprimida, están relegados a puestos inferiores en la clasificación del IDH. En la clasificación de 1995, la Federación Rusa aparece en el puesto 72, prácticamente empatado con Ecuador, puesto 73, mientras Cuba se ubica en el puesto 86. Se observa que los países situados en los últimos puestos del IDH mundial presentan condiciones similares caracterizadas por: inestabilidad, arbitrariedad, guerras tribales, ausencia absoluta de democracia y otras tragedias semejantes, lo cual les tiene sumidas en el atraso y la pobreza.

En América Latina también se ha emprendido reformas del Estado buscando una salida a los desequilibrios económicos, políticos y sociales. Las reformas han buscado:

- crear y ampliar la libertad individual, la participación social y el crecimiento económico;

- eliminar distorsiones económicas y políticas derivadas de actividades públicas monopólicas en áreas productivas;

- mejorar la capacidad reguladora reduciendo el riesgo regulatorio;

- limitar la discrecionalidad de la administración pública originada por las leyes vigentes y por su generalizada sobreabundancia; y,

- propender a mayores niveles de estabilidad política y social.

Los países latinoamericanos aparecen en la clasificación del IDH del año 1995 apenas en el puesto 31 con Chile, quien ocupaba el puesto precedente, pero fue desplazado por la República de Corea. Le siguen Costa Rica (34), Argentina (36), Uruguay (38) - hasta la clasificación del 94 el latinoamericano mejor situado pues ocupaba el puesto 30-, Panamá (45), Venezuela (46), México (49), Colombia (53) y Brasil (62). En el año 2015 las cosas cambian 
drásticamente y se aprecia un deterioro general: Chile desciende 7 puestos, Argentina se mantienen, Panamá y Perú mejoran 8 posiciones, Uruguay, Costa Rica, México y Venezuela son países con un deterioro significativo, pues pierden más de 24 posiciones entre 1990 y 2015.

Ecuador es un caso aparte y digno de análisis y evaluaciones serias. Luego de un avance importante en 1995 con mejoramiento del índice (ganancia de 16 posiciones de 89 a 73) respecto de 1990, empieza en despropósito de la economía y de la sociedad: en 2010 desmejoró el índice y se ubicó en el puesto 77; pero en 2015 la situación es preocupante: desmejora mucho hasta llegar a la ubicación 89. Es decir, regresamos al nivel de 1990, entonces, la pregunta es ¿ganamos o perdimos?

Al término de la década de 2010, el Ecuador no ha logrado concretar cambios que se había propuesto desde el comienzo de 1990, por ejemplo, la alta dependencia del petróleo. La infraestructura se mantiene dentro del ámbito excluyente de la administración pública; el desempeño económico es insatisfactorio; la inversión social, en consecuencia, se contrae mientras el obstruccionismo político arrecia.

Como país petrolero, pequeño y de ingreso medio alto, los ecuatorianos tenemos múltiples necesidades insatisfechas que acrecientan los niveles de pobreza. Nuestro país, luego de un período corto de estabilidad, ha retornado a ser un vivo ejemplo de la inestabilidad macroeconómica caracterizada por aumentos en el gasto público, déficit fiscal, tasas altas de endeudamiento y discrecionalidad del sector público. Como resultado, la tasa de crecimiento prácticamente se ha estancado. Es, por lo tanto, insuficiente para atender las necesidades de la sociedad ecuatoriana y disminuir la pobreza. Las clases más desposeídas reciben un mayor impacto toda vez que la incapacidad para resolver los problemas económicos conlleva la elevación de los niveles de desempleo y subempleo, postergando aún más las oportunidades de emprender iniciativas productivas eficientes.

Al parecer, los ecuatorianos hoy en día están a favor de modernizar la gestión pública y favorecer la participación privada en la inversión, administración y entrega de servicios públicos, como mecanismos para mejorar su bienestar social. Sin embargo, el obstruccionismo político ante la potencial pérdida de poder político y económico ha venido postergando innecesariamente las reformas estructurales que son requeridas para una administración 
pública eficiente. Luego de un período de fuerte hegemonía pública en la inversión de infraestructura se experimentó con la gestión pública directa a través de las empresas públicas, prácticamente menospreciando la gestión privada eficiente.

La frustración ciudadana se generaliza, aunque se concreten ciertas acciones como la escisión de Emetel en Andinatel y Pacifictel, las cuales, convertidas en compañías anónimas, dieron indicios de haber mejorado su desempeño y la actual CNT, cuyos resultados pueden ser positivos en números, la interconexión nacional por telefonía dio un giro trascendental pues cada día más ecuatorianos prefieren la telefonía celular.

A manera de conclusión, la existencia de países modernos y atrasados es de evidencia absoluta. Si se aspira al desarrollo humano, la forma nueva de hacer las cosas es una condición indispensable para elevar los niveles de bienestar social. No podemos ganar y volver a perder en desarrollo humano; debemos siempre mejorar, debemos aprender a capitalizar sobre lo actuado para avanzar y no retroceder. La pregunta que queda latente es ¿hemos perdido 25 años de desarrollo?

El nuevo rol del Estado es normativo y regulador de la competencia leal en la prestación de servicios y en la producción de bienes, abandonando las actividades productivas que mejor las desarrolla el sector privado. La participación privada en las actividades productivas no es un cuento, es una necesidad cierta para que el Estado se reserve sus tareas de regulación y bienestar social. A manera de escudo nos permite afrontar las crisis internacionales, que, por ser una economía abierta, siempre tendrán impacto y quien termina pagando son los mismos de siempre, la clase media baja para abajo.

\section{Referencias}

Crozier, Michel. 1989. Estado modesto, Estado moderno. Estrategia para el cambio. México: FCE.

Programa de las Naciones Unidas para el Desarrollo (PNUD). 1998. Informe sobre Desarrollo Humano, Prólogo. 